\title{
Aspectos bioéticos en la investigación fármaco-clínica en Chile
}

La posibilidad de disponer de un nuevo medicamento para prevenir, aliviar o curar una enfermedad requiere de un largo y costoso proceso de investigación. Desde el momento en que un investigador descubre una nueva molécula con potencial para ser usado como medicamento, hasta que se autoriza su uso terapéutico masivo en seres humanos, transcurren en promedio 10 a 15 años de investigación en que participan laboratorios académicos y/o farmacéuticos, públicos y/o privados, que patentan la molécula, e investigadores clínicos capaces de realizar el proceso que avalará su uso en seres humanos. En el mejor de los casos, sólo una de 100 moléculas con potencial terapéutico llegará a ser autorizada para tal fin, el resto no logrará aprobar el riguroso proceso que avala su eficacia y/o seguridad para el ser humano. Este complejo proceso requiere demostrar que la molécula es químicamente apropiada y que es eficaz y segura en modelos animales. Ulteriormente se realizan las tres fases de los estudios preclínicos en seres humanos. En los estudios de fase I, el producto es ensayado en centros médicos de alta complejidad en una serie de no más de 100 voluntarios. Si el potencial medicamento aprueba esta fase se realizan estudios de fase II que requieren entre 100 y algunos miles de voluntarios, para evaluar su eficacia y aumentar el conocimiento de su perfil de seguridad. Si el medicamento continúa demostrando que es seguro y eficaz y con efectos adversos aceptables, se pasa a los estudios de fase III, en que participan varios miles de voluntarios, Sólo luego de haber aprobado la fase III el medicamento estará en condiciones de ser evaluado por los organismos competentes para determinar si su uso terapéutico masivo puede ser autorizado.

La participación de seres humanos en investigación fármaco-clínica es indispensable y desde un punto de vista ético, debemos reconocer que si no se efectuase, no contaríamos con nuevos medicamentos que previenen y/o alivian sufrimiento y/o salvan vidas. Estas investigaciones en seres humanos aún no se pueden reemplazar por otros modelos que permitan extrapolar el comportamiento del medicamento, con el nivel de seguridad que se requiere para su uso masivo en la población. En este contexto es de fundamental importancia, que las personas que decidan participar voluntariamente en una investigación fármaco-clínica lo hagan luego de cumplir una serie de requisitos que resguarden su seguridad.

La persona que decide participar en un proyecto de investigación fármaco-clínico debe en primer lugar tener un conocimiento cabal y completo de todo lo referido a la investigación en que está aceptando participar. Una vez que ha recibido y entendido toda la información referente al medicamento en investigación, sus orígenes, los objetivos de la investigación, la experiencia previa con el medicamento, todos los efectos adversos conocidos, todos los procedimientos a que será sometido, los costos y sus eventuales compensaciones, los riesgos y los potenciales beneficios, debe decidir libre y voluntariamente su participación. Todo lo anterior debe quedar claramente explicitado en el "Consentimiento Informado", documento que tiene valor legal y que luego de ser aprobado en su redacción por un Comité de Bioética competente, debe ser firmado por el voluntario y el investigador. Las bases de este acuerdo son la absoluta voluntariedad de participación en la investigación, así como en su derecho de retirarse en cualquier momento sin dar explicación alguna y sin perjuicio alguno para el/ella. Se entiende que un sujeto participante de un estudio clínico es un voluntario solidario con su comunidad y que su seguridad debe ser protegida a toda costa por los investigadores.

Especiales consideraciones éticas se deben tener al realizar investigación en grupos o poblaciones vulnerables, clásicamente constituidas por cinco grupos: discapacitados en cuanto a su desarrollo, niños, ancianos, reclusos, enfermos mentales y minorías discriminadas o políticamente divididas. 
Las investigaciones originadas en países desarrollados que se realizan en países en desarrollo tienen la ventaja de ofrecer transferencia tecnológica, mejoramiento de infraestructura, formación de investigadores y personal de apoyo al país en desarrollo. Además esta modalidad de investigación puede resultar menos onerosa. Sin embargo, los paises en desarrollo deben plantear algunas exigencias: los estudios de fase I deben realizarse en el país de origen, el consentimiento informado debe ser redactado según la idiosincrasia local y se deben definir las compensaciones económicas y por riesgo.

¿Cuál es la situación de la investigación fármaco-clínica con participación de voluntarios chilenos? La experiencia de los últimos 25 años demuestra que la población chilena ha adquirido un nivel de información que le permite en un alto porcentaje entender lo que puede significar su participación en una investigación fármaco-clínica y por ende, puede dar su consentimiento libre e informado a participar, o no participar en un proyecto. La existencia creciente de investigadores con experiencia en buenas prácticas clínicas (reglamento internacional que regula la investigación clínica con seres humanos), de Comités de Ética serios que velan por el derecho de los potenciales voluntarios, y de Normativas Nacionales que regulan los ensayos clínicos sugieren que se puede realizar investigación clínica seria y responsable en nuestro país. La realización de investigaciones fármaco-clínicas adecuadamente reguladas y realizadas en voluntarios del país permite conocer con mayor precisión el comportamiento de nuevos medicamentos en nuestra población, lo que representa una ventaja al momento de licenciar los nuevos medicamentos en Chile. Es mejor conocer como se comportan en nuestra población que extrapolar el comportamiento de otras poblaciones en las que se puede haber realizado la investigación. Los beneficios secundarios que conlleva la investigación clínica de calidad son el mejoramiento de los estándares de manejo médico, la implementación de tecnologías de alto costo, el mejoramiento de los sistemas de información y de infraestructura, los cuales deben quedar a disposición de los establecimientos que contribuyeron a la investigación.

Sin embargo, es evidente que ningún beneficio puede eclipsar el primordial objetivo ético de todo estudio en seres humanos: velar por la seguridad del voluntario que decida participar libre e informadamente en un proyecto de investigación fármaco-clínica. En este sentido la seguridad más fiable la confiere que el proyecto cuente con un investigador responsable con buen criterio, informado y compasivo.

Drs. Miguel O'Ryan G. y Manuel Oyarzún G. Comité de Ética de Investigación en Seres Humanos (CEISH), Facultad de Medicina, Universidad de Chile.

\section{Bibliografía}

1.- BRODY B A, MCCULlOUGH L B, SHARP R R. Consensus and controversy in clinical research ethics. JAMA 2005; 294: 1411-4.

2.- SHUCHMAN M. Commercializing clinical trials-Risks and benefits the CRO boom. N Engl J Med 2007; 357: 1365-8.

3.- CIOMS 2002. Pautas éticas internacionales para la investigación biomédica en seres humanos.Ginebra (Traducción por el Programa Regional de Bioética OPS/OMS, Santiago de Chile, 2003). 